\title{
Variation Mitigation Model to Enhance Construction Performance of Public Building Projects in Tanzania
}

\author{
Yusuph B. Mhando ${ }^{1, *}$, Ramadhan S. Mlinga ${ }^{2}$, Henry M. Alinaitwe ${ }^{3}$ \\ ${ }^{1}$ Department of Construction Economics and Management, Makerere University, Kampala, Uganda \\ ${ }^{2}$ Department of Structural and Construction Engineering, University of Dar es Salaam, Dar es Salaam, Tanzania \\ ${ }^{3}$ College of Engineering, Design, Art and Technology, Makerere University, Kampala, Uganda \\ *Corresponding author: ybmhando@gmail.com
}

\begin{abstract}
Detrimental variations are variations which negatively impact the project performance resulting into scenarios such as cost overruns, time overruns, project abandonment, rework, disruption and conflicts. These scenarios have led to non-fulfillment of project objectives. The objective of the study was to develop a mitigation model that helps to mitigate detrimental variations in public building projects in Tanzania. Specifically, the research question was how can detrimental variations be minimised in building projects? Literature review was carried out. Data were collected using questionnaire survey, group discussion and case studies. In total, 143 professionals (architects, engineers, quantity surveyors and procurement officers) participated in the survey. Statistical analyses such as Analysis of Variance (ANOVA), T-test analysis, Spearman's rho correlation analysis and Principal Component Analysis (PCA) were used to analyse data and obtain relationships of variables. The analysis generated significant independent and dependent variables that formed the basis for the developed detrimental variation mitigation model. The model was validated through focus group discussion to test the model's usefulness, clarity and applicability. Findings from case studies suggest that building projects suffered detrimental variations. The developed model when used significantly contributes to reduction of detrimental variations. Project parties should use the developed best practice model to enhance performance of construction projects.
\end{abstract}

Keywords: building projects, detrimental variations, performance improvement, mitigation model, Tanzania

Cite This Article: Yusuph B. Mhando, Ramadhan S. Mlinga, and Henry M. Alinaitwe, "Variation Mitigation Model to Enhance Construction Performance of Public Building Projects in Tanzania." American Journal of Civil Engineering and Architecture, vol. 6, no. 3 (2018): 105-118. doi: 10.12691/ajcea-6-3-3.

\section{Introduction}

Due to detrimental variations construction projects often undergo scenarios such as cost overruns, time overruns, project abandonment, rework, disruption and conflicts. These scenarios have led to non-fulfillment of project objectives. Understanding the driving forces behind such problems is a necessity if performance of the construction projects is to be enhanced. Detrimental variations could be a major contributor to the above raised problems in the development of construction projects. Variations are caused by various factors and often result into disputes and dissatisfactions among the parties involved in construction projects [1]. Likewise, most construction projects, particularly in developing countries, usually suffer from cost and time overruns due to variations in project plans with the consequence of stagnated economic development [2,3]. In many countries, particularly developing countries, the government is the largest construction client [4]. Tanzania being a developing country has problems related to variations in executing its public building projects. Under normal circumstances, one would expect the project to be completed within the initially anticipated cost, time and quality, but reality takes the opposite direction. This tends to raise concern on infrastructure facilities developed by using meager public resources that fail to provide the anticipated value for money.

Park and Papadopoulou [5] argue that changes can lead to deviations from the sum stipulated in the contract. Therefore, it is very important to control variations in construction projects [1]. To date, several generic models for change management related issues have been developed. However, the main focus of these models was on how to handle changes that have already occurred. As a result, these models have inadequately addressed the preventive measures of detrimental variations from the inception to completion stages of the project. For instance, Senaratne and Sexton [6] proposed a model that contributed to theory and knowledge-based project change process; Motawa [7] proposed a change process model that is intended to enable project teams to manage changes; and Moghaddam [8] proposed a change management and change process model tailored to the requirements of the Iranian construction industry. Others are Kolawole et al. [9] who provided the necessity for an easily adoptable method for change order management for the Nigerian construction industry, and Hao et al. [10] who proposed a generic change process model based on the syntheses of several change process models reviewed in the literature. 
In fact, many previous studies on the subject matter have mainly focused on the reactive approach of managing variations. That is, the emphasis was to improve efficiency in handling changes after they have already occurred. Consequently, this approach has led to severe and frequent costly litigation between project parties over the responsibility for cost overruns and delays. While recommendations from those studies are beneficial, they are not sufficient to manage the complex process of change, particularly when there are different change causes and consequences in the project life cycle. Moreover, most of the existing models from the literature are difficult to use as they focus on the use of complex ICT applications on the advanced construction systems. This situation renders it difficult to put into practice those models especially in developing countries like Tanzania, where the application of ICT software and hardware is still low. Ideally, it is the objective of this study to develop a model as an alternative proactive approach that can be used by project parties to enhance construction performance.

\section{Literature Review}

\subsection{The Concept of Detrimental Variations}

Detrimental variations and their subsequent effects in building projects occur due to several reasons. Most public building projects are liable to variations that might be caused by change of mind or any unforeseen scope of the project raised by any of the project participants. Likewise, the engineers' or architects' review of the design may bring about changes to improve or optimize the design and the operation of the project [11]. Arain and Pheng [12] affirm that variations may be beneficial (advantageous) or detrimental (disadvantageous), the latter being the main focus of this research work. Normally, beneficial variations are those variations which positively impact the project in terms of cost, time and quality. Conversely, detrimental variations are variations which negatively impact the project resulting into scenarios such as escalated budget, elongated schedule, project abandonment, rework, disruption and conflicts.

\subsection{Variation Modeling}

Various studies were carried out on modeling of change processes and change management in construction projects. However, the main focus of these studies was to address how changes affect various aspects of delivery of construction projects. Studies such as $[7,8]$ consider cost and time overruns as the main impacts of variations. Other areas of concern included labour productivity, quality issues, rework, disruption and value for money in the whole life cycle of the project. Love et al. [13] developed a rework reduction model for construction projects in Australia. The model consists of two primary parts, namely design development and production processes. Ideally, the project facilitator should undertake an audit and sign off at the end of each design stage. This ensures that what has been specified by the client has been in-built into the design and is documented accordingly. The project team should be selected from weighted prequalification criteria, past performance, and through the process of negotiation. This would be an alternative to traditional price-driven selection procedures that limit the flexibility of the designers and contractors to explore innovative avenues that can result in optimal performance. Relatively, the production process emphasis was on the contractors to use their understanding of constructability and knowledge acquired from the design process to plan and coordinate the works so that subcontractors know "when and where" they are supposed to conduct their tasks. The model was developed by gathering the information from literature review and 161 completed projects using a questionnaire survey. Multiple analytical techniques were used to determine the significant variables that contributed to the rework in projects. The rework reduction model helps to stimulate inter-organizational relations and promote teambuilding during the formative stages of a project, which is essential for reducing design-related rework. In fact, the innovation of previous researchers on change process and change management has contributed significantly to the construction management domain. These researchers include Hao et al. [10] who investigated on change management in construction projects in Canada; and Hwang and Low [14] who looked into the status, importance and impact of construction project change management in Singapore. However, the reduction of detrimental changes in public building projects in Tanzania would require a mitigation model as an alternative proactive approach to improved performance in such projects.

\subsection{Mitigating Factors}

Mitigating factors of detrimental variations provide practical informed decisions to professionals for effective strategic management of detrimental variations [15]. Memon et al. [1] argue that in order to improve construction performance, it is very important to alleviate detrimental variations in construction projects. Hao et al. [10] proposed clear design specifications before bidding and curbing corruption in procurement process as the potential mitigation measures of detrimental variations in construction projects in Canada. Mlinga [16] argues that the procurement process rules must be clear, open, well understood and applied equally to all parties to the process. The application of the highest ethical standards will help ensure the best achievable procurement outcomes with constrained corruption practices in the tendering process.

Traditionally, any construction project tends to develop in a sequential arrangement and involves interaction among different project participants. Thus, a clear and thorough project brief is important as it helps in clarifying the project objectives to all project participants. Consequently, this may reduce design errors and noncompliance with owner's requirements and hence minimize the magnitude of detrimental variations in all stages of project development. Subramani et al. [17] found mitigating factors in the Indian construction industry as comprehensive site investigation and potential control for variations orders to arise through contractual clauses. Moghaddam [8] found that variation logic, variation justification and valuation of indirect effects of variations 
were significant mitigating factors of detrimental variations in the Iranian construction industry.

Other researchers have looked into factors that mitigate detrimental variations. For instance, Memon et al. [1] based on a study conducted in Malaysia identified four factors, namely collective effort by client, consultant and contractor to control variation orders; clear design specifications; client involvement during construction phase, and prompt written approval procedures. Other identified factors that could curb detrimental variations include engagement of a project manager to manage the project [18]; teamwork spirit among project parties [19]; proper use of collected and organised project data compiled by client [20]; use of knowledge base of previous related projects [21]; proper utilization of work break down structures (WBS) [22]; restricted prequalification system for awarding projects [23]; use of project scheduling techniques; and clarity of variation order procedures [3]. From the synthesis of literature review, a total of seventeen variation mitigation factors as contributing factors of construction performance were identified and summarised in Table 1. However, the findings from those previous studies have demonstrated similarities and differences pertaining to detrimental variation mitigating factors. This scenario might be due to differences in methodologies and locations used for the investigations.

Table 1. Variation Mitigation Factors

\begin{tabular}{|c|c|c|}
\hline Code & Variations mitigation factors & Source \\
\hline CF01 & $\begin{array}{l}\text { Effort by client, consultant and contractor to } \\
\text { control variation orders }\end{array}$ & [1] \\
\hline CF02 & Comprehensive site investigations & [17] \\
\hline CF03 & Clear project specifications & [1] \\
\hline CF04 & $\begin{array}{l}\text { Engagement of a project manager to manage the } \\
\text { project }\end{array}$ & [18] \\
\hline CF05 & Teamwork spirit & [19] \\
\hline CF06 & Proper use of project data compiled by client & [20] \\
\hline CF07 & Variation logic and justification & [8] \\
\hline CF08 & $\begin{array}{l}\text { Use of knowledge base of previous related } \\
\text { projects }\end{array}$ & [21] \\
\hline CF09 & Clients involvement during construction phase & {$[1]$} \\
\hline CF10 & Prompt written approval procedures & {$[1]$} \\
\hline CF11 & Use of proper project scheduling techniques & [3] \\
\hline CF12 & Clarity of variation order procedures & [3] \\
\hline CF13 & Proper utilization of work break down structures & [22] \\
\hline CF14 & Initiatives aimed at curbing corruption & {$[10,16]$} \\
\hline CF15 & Valuation of indirect effects & {$[8]$} \\
\hline CF16 & $\begin{array}{l}\text { Control for variation orders to arise through } \\
\text { contractual clauses }\end{array}$ & {$[17]$} \\
\hline CF17 & Restricted tendering method for awarding projects & [24] \\
\hline
\end{tabular}

$\mathrm{CF}=$ Contributing Factor

\subsection{Construction Performance Dimensions}

Ibbs [25] identifies three performance dimensions on project delivery in the construction industry as good cost, schedule, and productivity performance. Simpeh et al. [26] disclose the same performance dimensions in the South African construction industry. Alinaitwe [27] reveals seven construction performance dimensions in the construction industry as productivity, profitability, quality, innovation, efficiency, quality of work life, and effectiveness. Taggart et al. [28] identify production efficiency, cost reduction, reduction of rework and defects as potential performance dimensions in the Irish construction industry. Arain [15] identified the main criteria of construction performance as time, cost, quality and safety conditions. Moreover, it is argued that in modern construction project procurement the goal is inspiring clients, consultants, contractors and suppliers to work together towards improving quality, lowering costs, dispute mitigation, innovation, and sharing risks [29]. Several common factors that lead to project performance were initially identified from previous studies. Some of these factors are related or overlapping each other. After the analysis, seven factors and their sources outlined in Table 2 are shortlisted as the potential construction performance dimensions (CoPDs). However, these dimensions can be realized through proper control of detrimental variations at all stages of building project development, particularly at construction stage. In fact, in any construction project, almost all clients are interested in obtaining fully functional facilities completed in the anticipated time, cost, quality and scope.

Table 2. Construction Performance Dimensions (CoPDs)

\begin{tabular}{|c|c|c|}
\hline Code & Construction performance dimensions & Reference(s) \\
\hline CoPD1 & Cost performance & {$[25,26]$} \\
\hline CoPD2 & Time performance & {$[25,26]$} \\
\hline CoPD3 & Undisputed parties & {$[29]$} \\
\hline CoPD4 & Restricted rework and demolition & {$[28]$} \\
\hline CoPD5 & Productivity performance & {$[25,26]$} \\
\hline CoPD6 & Quality performance & {$[27]$} \\
\hline CoPD7 & Safety conditions & {$[15,27]$} \\
\hline
\end{tabular}

\subsection{Theoretical Framework}

This study is modeled on theories and concepts that are found relevant to the research question being investigated. Overall, building project as a unit of analysis can be thought of as a system composed of, but not limited to, subsystems such as finance, site operations, planning, monitoring and control, communication, procurement, budgeting and accounting systems. Therefore, the systems theory was found to be relevant for this study. The success of any building project mainly depends on the collective responsibilities of the project team to achieve project objectives. The collective actions and interrelationships of the project participants make the theory appropriate for analysis and for explaining the variation phenomenon in building projects. Building project being an open system which is comprised of subsystems takes resources (input) through process to give out finished work (output). In this case, it is apparent that, any changes in any subsystem affect other subsystems.

According to Chikere and Nwoka [30] systems theory focuses on the arrangement of and relationship between the parts and how they work together as a whole. The way the parts are organized and how they interact with each other, determine the properties of that system. Essentially, 
the systems theory gives a way of thinking about complex process so that the interrelationships of the parts and their influence upon the effectiveness of the total process can be understood, analysed and improved. Subsequently, the theory was applied to business organisations [30].

Thus, this research explored and considered system approach to mitigating the problem of detrimental variations in the delivery of public building projects in Tanzania. A proactive system comprising of relevant subsystems developed herein, would not only pre-empt flaws in building projects, but would also help the entire project team to act prior to the occurrence of detrimental variations.

\section{Materials and Methods}

\subsection{Research Design}

The research design used for this study was a survey design which relied on a pragmatic approach of both quantitative and qualitative research methods to generate data needed for the analysis. The adoption of both quantitative and qualitative approaches helps to maximize the strengths and minimize the limitations of each technique [31].

\subsection{Population and Sampling}

Population of the study included all architects, engineers, quantity surveyors, and procurement and supplies officers registered and engaged in public building projects in Tanzania. The sampling frame included local registered professionals (284 Architects and 198 Quantity Surveyors with AQRB, 2090 Civil Engineers with ERB and, 525 Procurement and Supplies Officers with PSPTB) in Tanzania. Based on the heterogeneous nature of public building projects in Tanzania, a purposive sampling technique was used to obtain a representative sample for the study. Palinkas et al. [32] affirm that purposive sampling is a useful technique widely used in research for the identification and selection of information-rich cases for the most effective use of limited resources. Tongco [33] insists that a purposive sampling technique is a deliberate choice of an informant due to the qualities that the informant possesses. Purposive sampling defines a process where a researcher uses own judgement to select a group of people who know about the problem. Moreover, this type of sampling technique is convenient and cost effective [34].

\subsection{Instrument and Data Collection}

Questionnaires were used for the study. A pilot study was conducted with one architect, four engineers, three quantity surveyors and one procurement officer to test whether the wording was clear, questions were intelligible and if there was any research bias. Through feedback obtained, corrections were made to improve the format, layout, questions and the overall content of the questionnaire. The validated questionnaire form was divided into two main sections. Section one required the respondents to give their general information and section two required them to rate the predictor and response variables using five-point Likert scale viz-a-viz: strongly disagree $=1$; disagree $=2$; neutral $=3$; agree $=4$ and strongly agree $=5$. The rated 24 constructs were extracted from an extensive literature review mainly within the construction management context. The Likert Scale Rating System (LSRS) has been used successfully by many researchers such as Memon et al. [1] and Mohammad et al. [35] in their studies. A total of 183 questionnaires were distributed to construction practitioners (architects, engineers, quantity surveyors and procurement officers) in Tanzania, contacted in person to get individual perceptions. Telephone call and short message system (SMS) reminders were used to remind the respondents to fill the questionnaire form. This resulted into 143 valid responses, constituting a response rate of 78 per cent, which is considered adequate for data analysis. Additionally, focus group discussions and case studies were used for collecting data about the subject matter being investigated.

\subsection{Focus Group Discussion}

Focus group discussion as a method of data collection was used to validate the developed detrimental variation mitigation model. The model was developed by using the independent and dependent variables generated from the analysis. Section 3.7 presents more details on how the model was developed. In order to validate the model, relevant stakeholders in the construction industry were consulted with regard to the model's (1) applicability, (2) usefulness, (3) clarity, (4) significance and (4) areas of improvement. It was considered difficult to validate the developed model by the application method as this would need a number of years before a fair judgement of the model's validity could be achieved. Fellows and Liu [36] ascertain that focus group discussion method is a valuable approach as it provides an environment for homogeneous groups of professionals and experts to interact and freely exchange ideas and opinions, and at the end of the discussion, establish a consensus view on a particular topic. Wong [37] point out that the approach involves formulating research questions, developing protocols, soliciting participants, arranging venues, facilitating focus groups, transcribing, analysing data, and reporting the findings.

Stewart at al. [38] argue that though there are no firm guidelines regarding the number of focus groups, most studies use at least two groups and few studies use more than four groups. Kombo and Tromp [31] argue that a focus group is usually composed of 6 to 8 individuals who share certain characteristics which are relevant for the study. In this study, two focus groups each with six participants representing three groups of construction practitioners (clients, consultants and contractors) were formed. The first focus group participants included two architects, two quantity surveyors and two engineers. The second focus group comprised two procurement officers, two engineers, one architect and one quantity surveyor. On average, the participants had 16 years of experience in various types of building projects ranging from small to large projects. 
The focus group discussions were conducted in Arusha City as a convenient location for the participants. Each group session lasted for 105 minutes including a health break of 15 minutes, but with the time allocation used flexibly. Wong [37] points out that the duration of discussion is usually 45 to 90 minutes. However, Spillane and Oyedele [39] conducted focus group discussion with durations ranged from twenty to seventy five minutes. The moderator guided the group discussion by using a guide to obtain information from participants. However, the moderator was flexible and focused in guiding the participants with regard to the topic under discussion. Cohen et al. [40] insist that focus group requires skillful facilitation and management by the researcher. Assistants (note takers) were able to assist the moderator to transcribe notes from the discussion. The focus group interviewers used a note-taker, rather than a tape-recorder, because recording a discussion can make participants frightened and uneasy, especially in organizational contexts [41].

In order to elicit relevant information, participants were provided with short presentation of the research, model contents and focus group discussion areas. PowerPoint projectors and flip charts were used for presentation. Participants were provided with focus group discussion protocol which comprised brief introduction of the research, purpose of the focus group discussion, participation request, participant's particulars and structured questions as provided in Table 3. It is argued that focus groups are useful for developing themes, topic and schedules flexibly for subsequent interviews and/or questionnaires [40]. Each of the five discussion areas was presented on a flip chart sheet to enhance participants understanding and to prompt discussion. With each theme presented in Table 3, participants were asked to interact and freely exchange ideas and opinions, and at the end of the discussion, establish a consensus view.

Table 3. Questions on model's applicability, clarity, usefulness and areas of improvement

1. How would you rate the model applicability in reducing detrimental variations in terms of its structure, relevance and amalgamation?

2. To what extent the model clarity influences obligations, communication, knowledge, skills and integrity to stakeholders?

3. How the model is considered useful to curb detrimental variations in construction projects with respect to quality increase and reducing disputes, cost, and time?

4. In your opinion what is the significance of the model in construction projects?

5. In your opinion how can the model get improved?

\subsection{Case Study Sites}

A Case Study is defined as an empirical inquiry that investigates a phenomenon and studies its contextual conditions, especially which might be highly relevant to the phenomenon of study [42]. Case Studies provide an opportunity to study the case in its natural setting by taking a holistic approach. This helps to understand a complex phenomenon such as variations in public building projects. In general, Case Studies are the preferred strategy when the researcher is dealing with "how" or "why" question being asked about a contemporary set of events over which the investigator has little or no control [42].

Thus, a sample of three sites was purposefully chosen. The selection criteria of the Case Studies were based on: (1) reinforced concrete frame buildings; (2) public financed buildings that are rich in information; (3) public buildings that are accessible with minimum time and cost. Based on these criteria, three Case Studies were drawn for the study. Case Study one in Figure 1 was the proposed residential apartments located in the Arusha City. Case Study two in Figure 2 was the proposed apartment block located in Arusha City. Case Study three in Figure 3 was the proposed building comprised classrooms, laboratories and offices located in Arusha City. The selected case studies were to provide in-depth knowledge and a better understanding of the factors of detrimental variations. Consequently, the data collected from case studies were used to validate the model.

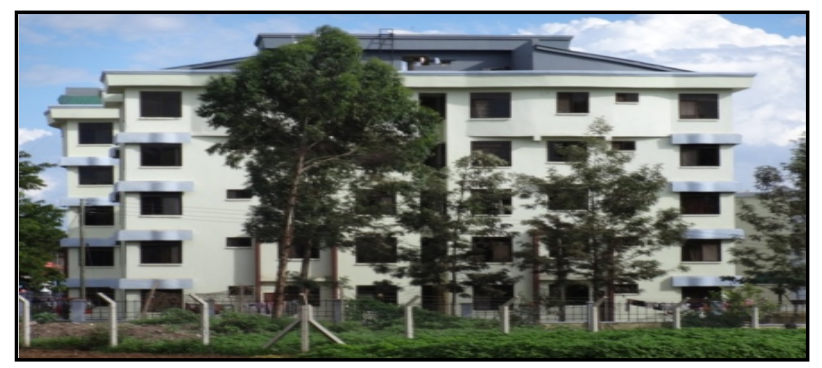

Figure 1. Residential Block - Case Study 1



Figure 2. Apartment Block - Case Study 2

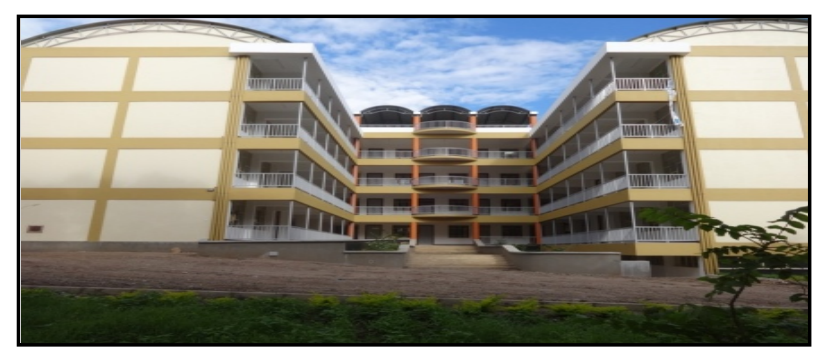

Figure 3. Teaching Facilities Block - Case Study 3

\subsection{Data Analysis}

The data collected were carefully analysed using Statistical Package for Social Sciences (SPSS) version 17. Several statistical analyses as illustrated in Table 4 were performed to examine the underlying relationships between dependent and independent variables. 
Table 4. Statistical analysis of the empirical data

\begin{tabular}{|c|c|}
\hline Item of Assessment & Method of Assessment \\
\hline $\begin{array}{l}\text { Internal consistency of the questionnaire } \\
\text { items }\end{array}$ & $\begin{array}{l}\text { Cronbach's alpha } \\
\text { reliability testing }\end{array}$ \\
\hline $\begin{array}{l}\text { Differences of perceptions on the contributing } \\
\text { factors (CFs) for construction performance }\end{array}$ & $\begin{array}{l}\text { Homogeneity test } \\
\text { ANOVA (> groups) }\end{array}$ \\
\hline Assessing significance in rating the variables & $\begin{array}{l}\text { One-sample t-test } \\
\text { analysis }\end{array}$ \\
\hline Association level between variables & $\begin{array}{l}\text { Spearman's rho } \\
\text { correlation analysis }\end{array}$ \\
\hline $\begin{array}{c}\text { Dimensionality reduction of the predictor } \\
\text { variables }\end{array}$ & $\begin{array}{l}\text { Principal Component } \\
\text { Analysis (PCA) }\end{array}$ \\
\hline
\end{tabular}

\subsection{Model Development}

In developing the model, Spearman's Rho correlation method and PCA were the two essential tools used for analyzing data to generate significant independent and dependent variables needed for formulating a detrimental variation mitigation model. Spearman's rho correlation is considered most suitable to test the association level between any two variables and to show the probability of the association. PCA is normally performed to reduce the dimensionality of the predictor variables [43]. In this case, those components that contributed significantly to the extracted factors were qualified as an input for developing the model.

From the Spearman's rho correlation analysis, the independent variables that were positively correlated with dependent variables and had significance levels at confidence level of 95 percent (p-value less than 0.05) were examined. PCA was performed to retain only those components that contributed significantly to the extracted factors. In line with Suryanarayana and Mistry [43], only those components with Eigenvalues greater than one were retained for inclusion in the model.

Developing the best practice model requires further steps for checking its validity and consistency. The resulting model was validated to test the model's usefulness, clarity and applicability in ensuring that it adds value to building projects. As proposed by Fellows and
Liu [36], a focus group discussion technique was used to validate the model.

\section{Results and Discussions}

\subsection{Reliability Testing}

The Cronbach's alpha coefficient values in Table 5 authenticate that the 24 rated items from the questionnaire form a scale that has reasonable internal consistency reliability. The obtained Cronbach's alpha coefficient of 0.87 and 0.73 are within the acceptable range of between zero and one [44]. Impliedly, the survey instrument used was reliable and that an agreement exists between construction industry practitioners in rating the variables accordingly.

Table 5. Results of Cronbach's alpha reliability test

\begin{tabular}{|c|c|c|c|}
\hline Constructs & $\begin{array}{c}\text { Cronbach's } \\
\text { alpha value }\end{array}$ & $\begin{array}{c}\text { No. of } \\
\text { items }\end{array}$ & $\mathbf{N}$ \\
\hline $\begin{array}{c}\text { Contributing factors (CFs) for } \\
\text { construction performance }\end{array}$ & 0.87 & 17 & 143 \\
\hline $\begin{array}{c}\text { Construction performance } \\
\text { dimensions (CoPDs) }\end{array}$ & 0.73 & 7 & 143 \\
\hline
\end{tabular}

\subsection{Demographic Survey of Respondents}

Table 6 shows that 79 (55 per cent) respondents were representatives of the clients. This has made the study worthwhile because the study was on public building projects. From Table 6, it is shown that 70 per cent of respondents have worked for more than 5 years in the industry. The respondents' appreciable work experience implies that the respondents have adequate knowledge of construction projects and the associated risks. Consequently, the respondents were able to understand the field problems and give feedback that was considered reliable and trustworthy.

Table 6. Demographics data about respondents

\begin{tabular}{|c|c|c|c|c|c|c|}
\hline \multicolumn{2}{|c|}{ Distribution of the respondents according to: } & \multirow{2}{*}{$\begin{array}{c}\text { Architect } \\
1 \\
\end{array}$} & \multirow{2}{*}{$\begin{array}{c}\text { Engineer } \\
58\end{array}$} & \multirow{2}{*}{$\begin{array}{c}\text { Quantity } \\
\text { Surveyor } \\
9 \\
\end{array}$} & \multirow{2}{*}{$\begin{array}{c}\begin{array}{c}\text { Procurement } \\
\text { Officer }\end{array} \\
11 \\
\end{array}$} & \multirow{2}{*}{$\begin{array}{c}\text { Total } \\
79 \\
\end{array}$} \\
\hline & Clients & & & & & \\
\hline 1уре 01 & Consultants & 10 & 10 & 18 & 1 & 39 \\
\hline & Contractors & 1 & 16 & 8 & 0 & 25 \\
\hline \multicolumn{2}{|l|}{ Total } & 12 & 84 & 35 & 12 & 143 \\
\hline \multirow{3}{*}{ Education level } & Undergraduate & 10 & 67 & 28 & 5 & 110 \\
\hline & Masters Degree & 2 & 16 & 7 & 7 & 32 \\
\hline & Doctoral degree & 0 & 1 & 0 & 0 & 1 \\
\hline \multicolumn{2}{|l|}{ Total } & 12 & 84 & 35 & 12 & 143 \\
\hline \multirow{2}{*}{ Gender } & Male & 10 & 76 & 24 & 9 & 119 \\
\hline & Female & 2 & 8 & 11 & 3 & 24 \\
\hline \multicolumn{2}{|l|}{ Total } & 12 & 84 & 35 & 12 & 143 \\
\hline \multirow{6}{*}{ Work experiences } & $0-5$ Years & 5 & 21 & 13 & 4 & 43 \\
\hline & 6-10 Years & 3 & 21 & 9 & 4 & 37 \\
\hline & 11-15 Years & 1 & 11 & 7 & 1 & 20 \\
\hline & 16-20 Years & 1 & 10 & 2 & 3 & 16 \\
\hline & 21-25 Years & 0 & 9 & 0 & 0 & 9 \\
\hline & $>25$ Years & 2 & 12 & 4 & 0 & 18 \\
\hline \multicolumn{2}{|l|}{ Total } & 12 & 84 & 35 & 12 & 143 \\
\hline
\end{tabular}

Source: Analysed Data (2018). 


\subsection{Test of Homogeneity}

According to Fellows and Liu [36], ANOVA is a statistical method used to test whether there is a significance difference between means of responses of more than two independent populations. Table 7 provides the correlated predictor variables that have significance level of ( $p<0.05$ ) less than 5 per cent. It signifies that the four characteristics of respondents (type of organization, professional background, education level and work experiences) attribute significant difference of respondents' perceptions towards mitigating factors of detrimental variations that improve construction performance.

Table 7. Test of Homogeneity of Variances (ANOVA)

\begin{tabular}{|c|c|c|c|c|}
\hline Construction performance contributing factor & Type of Organization & $\begin{array}{l}\text { Professional } \\
\text { Background }\end{array}$ & $\begin{array}{c}\text { Education } \\
\text { Level }\end{array}$ & $\begin{array}{c}\text { Work } \\
\text { Experiences }\end{array}$ \\
\hline Effort by client, consultant and contractor to control variation orders & $0.00^{*}$ & $0.0^{*}$ & $0.01 *$ & $0.01^{*}$ \\
\hline Comprehensive site investigations & $0.00 *$ & 0.26 & $0.03^{*}$ & $0.02 *$ \\
\hline Clear design specifications & $0.04 *$ & $0.03^{*}$ & 0.48 & 0.87 \\
\hline Engagement of project manager to manage the project & $0.01^{*}$ & 0.48 & $0.02 *$ & 0.79 \\
\hline Teamwork spirit & 0.09 & $0.02 *$ & $0.00^{*}$ & 0.73 \\
\hline Proper use of project data compiled by client & 0.17 & 0.06 & $0.04^{*}$ & 0.59 \\
\hline Variation logic and justification & 0.62 & 0.42 & $0.02 *$ & 0.55 \\
\hline Use of knowledge base of previous related projects & 0.49 & 0.62 & $0.00^{*}$ & 0.37 \\
\hline Clients involvement during construction phase & 0.30 & $0.00^{*}$ & $0.04 *$ & 0.10 \\
\hline Prompt written approval procedures & 0.13 & $0.01^{*}$ & $0.00^{*}$ & 0.31 \\
\hline Proper project scheduling (planning) & $0.03^{*}$ & 0.89 & $0.04 *$ & $0.03 *$ \\
\hline Clarity of variation order procedures & 0.25 & 0.63 & $0.03^{*}$ & $0.01^{*}$ \\
\hline Proper utilization of work break down structures (WBS) & 0.09 & 0.55 & $0.00^{*}$ & 0.18 \\
\hline Initiatives aimed at curbing corruption & 0.83 & $0.02 *$ & 0.11 & 0.29 \\
\hline Valuation of indirect effects & 0.70 & 0.07 & $0.00 *$ & $0.00^{*}$ \\
\hline Control for variation orders to arise through contractual clauses & 0.54 & $0.00^{*}$ & 0.06 & 0.75 \\
\hline Restricted tendering method for awarding projects & 0.84 & 0.61 & 0.42 & 0.60 \\
\hline
\end{tabular}

Notes: Significance $(\mathrm{p}<0.05)$; Insignificance $(\mathrm{p}>0.05)$

Table 8. Results of correlation analysis

\begin{tabular}{|c|c|c|c|c|c|c|c|c|}
\hline \multirow{2}{*}{ Factors } & & \multicolumn{7}{|c|}{ Construction Performance Dimensions (CoPDs) } \\
\hline & & CoPD1 & CoPD2 & CoPD3 & CoPD4 & CoPD5 & CoPD6 & CoPD7 \\
\hline \multirow{2}{*}{ CF01 } & Spearman's rho & $0.27^{*}$ & $0.33^{*}$ & $0.20^{*}$ & -0.04 & $0.17^{*}$ & 0.15 & 0.01 \\
\hline & Sig. (2-tailed) & 0.00 & 0.00 & 0.02 & 0.66 & 0.05 & 0.07 & 0.87 \\
\hline \multirow{2}{*}{ CF02 } & Spearman's rho & 0.16 & $0.31^{*}$ & $0.17^{*}$ & 0.12 & 0.08 & -0.08 & -0.08 \\
\hline & Sig. (2-tailed) & 0.06 & 0.00 & 0.05 & 0.16 & 0.34 & 0.32 & 0.33 \\
\hline \multirow{2}{*}{ CF03 } & Spearman's rho & $0.34^{*}$ & $0.44^{*}$ & 0.12 & 0.13 & 0.02 & 0.00 & -0.06 \\
\hline & Sig. (2-tailed) & 0.00 & 0.00 & 0.15 & 0.14 & 0.84 & 0.97 & 0.47 \\
\hline \multirow{2}{*}{ CF04 } & Spearman's rho & $0.30^{*}$ & $0.33^{*}$ & $0.27^{*}$ & $0.25^{*}$ & 0.10 & 0.00 & 0.02 \\
\hline & Sig. (2-tailed) & 0.00 & 0.00 & 0.00 & 0.00 & 0.26 & 0.98 & 0.73 \\
\hline \multirow{2}{*}{ CF05 } & Spearman's rho & $0.21^{*}$ & $0.28^{*}$ & $0.21^{*}$ & 0.01 & 0.11 & 0.02 & -0.01 \\
\hline & Sig. (2-tailed) & 0.01 & 0.00 & 0.02 & 0.91 & 0.20 & 0.84 & 0.95 \\
\hline \multirow{2}{*}{ CF06 } & Spearman's rho & 0.02 & $0.18^{*}$ & 0.16 & 0.08 & $0.17^{*}$ & 0.02 & 0.06 \\
\hline & Sig. (2-tailed) & 0.79 & 0.04 & 0.06 & 0.37 & 0.04 & 0.78 & 0.47 \\
\hline \multirow{2}{*}{ CF07 } & Spearman's rho & 0.09 & 0.07 & 0.14 & 0.15 & $0.20^{*}$ & 0.16 & 0.10 \\
\hline & Sig. (2-tailed) & 0.28 & 0.42 & 0.10 & 0.07 & 0.02 & 0.05 & 0.22 \\
\hline \multirow{2}{*}{ CF08 } & Spearman's rho & 0.06 & $0.23^{*}$ & $0.20^{*}$ & 0.13 & $0.22^{*}$ & 0.14 & 0.07 \\
\hline & Sig. (2-tailed) & 0.49 & 0.01 & 0.02 & 0.14 & 0.01 & 0.09 & 0.42 \\
\hline \multirow{2}{*}{ CF09 } & Spearman's rho & $0.29^{*}$ & $0.21^{*}$ & 0.10 & 0.05 & -0.02 & -0.13 & -0.03 \\
\hline & Sig. (2-tailed) & 0.00 & 0.01 & 0.24 & 0.57 & 0.80 & 0.13 & 0.70 \\
\hline \multirow{2}{*}{ CF10 } & Spearman's rho & $0.23^{*}$ & $0.28^{*}$ & -0.00 & 0.08 & 0.10 & 0.01 & -0.01 \\
\hline & Sig. (2-tailed) & 0.01 & 0.00 & 0.96 & 0.34 & 0.26 & 0.93 & 0.91 \\
\hline \multirow{2}{*}{ CF11 } & Spearman's rho & 0.15 & 0.16 & 0.13 & 0.05 & $0.18^{*}$ & $0.19^{*}$ & $0.17^{*}$ \\
\hline & Sig. (2-tailed) & 0.08 & 0.06 & 0.13 & 0.57 & 0.03 & 0.02 & 0.03 \\
\hline \multirow{2}{*}{ CF12 } & Spearman's rho & $0.20^{*}$ & $0.25^{*}$ & 0.16 & $0.18^{*}$ & 0.11 & 0.04 & 0.16 \\
\hline & Sig. (2-tailed) & 0.02 & 0.00 & 0.06 & 0.03 & 0.18 & 0.61 & 0.06 \\
\hline \multirow{2}{*}{ CF13 } & Spearman's rho & 0.01 & 0.10 & $0.17^{*}$ & -0.01 & $0.17^{*}$ & 0.15 & 0.06 \\
\hline & Sig. (2-tailed) & 0.89 & 0.24 & 0.04 & 0.95 & 0.05 & 0.07 & 0.47 \\
\hline \multirow{2}{*}{ CF14 } & Spearman's rho & 0.10 & $0.19^{*}$ & 0.16 & 0.01 & $0.22^{*}$ & $0.20^{*}$ & 0.12 \\
\hline & Sig. (2-tailed) & 0.26 & 0.03 & 0.05 & 0.87 & 0.01 & 0.02 & 0.15 \\
\hline \multirow{2}{*}{ CF15 } & Spearman's rho & 0.05 & 0.12 & $0.30^{*}$ & 0.03 & $0.24^{*}$ & $0.18^{*}$ & $0.25^{*}$ \\
\hline & Sig. (2-tailed) & 0.60 & 0.15 & 0.00 & 0.69 & 0.01 & 0.03 & 0.00 \\
\hline \multirow{2}{*}{ CF16 } & Spearman's rho & 0.09 & 0.14 & -0.03 & -0.01 & -0.03 & -0.00 & -0.08 \\
\hline & Sig. (2-tailed) & 0.30 & 0.10 & 0.72 & 0.90 & 0.73 & 0.98 & 0.32 \\
\hline \multirow{2}{*}{ CF17 } & Spearman's rho & -0.01 & 0.15 & 0.10 & -0.05 & $0.27^{*}$ & $0.18^{*}$ & 0.14 \\
\hline & Sig. (2-tailed) & 0.88 & 0.07 & 0.24 & 0.56 & 0.00 & 0.03 & 0.11 \\
\hline
\end{tabular}

Note: *.Correlation is significant at the 0.05 level (2-tailed); List wise $\mathrm{N}=143$ 


\subsection{Correlation Analysis}

Correlation analysis results presented in Table 8 demonstrate that seven variables were found to be significantly correlated with cost performance dimension (CoPD1) and had significance levels at confidence level of 95 per cent ( $p$-value less than 0.05). Relatively, other significantly correlated variables include eleven variables for CoPD2; seven for CoPD3; two for CoPD4; nine for CoPD5; four for CoPD6 and two for CoPD7. These results demonstrate that the seven construction performance dimensions (CoPDs) exhibit different association levels and were influenced by the contributing factors (CFs). However, no contributing factor was found to be significant and correlate to all CoPDs.

\subsection{Principal Component Analysis (PCA)}

A PCA was carried out to eliminate predictor variables with Eigenvalues less than one. Suryanarayana and Mistry [43] argue that the most widely used criterion is to retain only those components with Eigenvalues greater than one. Impliedly, those components that contributed significantly to the extracted factors were qualified as an input for developing the research model. A PCA is performed to reduce the dimensionality of the predictor variables [43]. Kaiser-Meyer-Olkin (KMO) value close to one indicates that the patterns of correlations are relatively compact and so factor analysis should yield distinct and reliable factors. It also specifies that values between 0.00 and 0.49 do not factor; values between 0.5 and 0.7 are mediocre; values between 0.7 and 0.8 are good; values between 0.8 and 0.9 are great; and values above 0.9 are superb. From Table 10, the determined KMO value was 0.84, which falls into the range of being great. Furthermore, the determined approximate Chi-square in the Bartlett's test of sphericity was 870.10 and the significance was 0.00 . These values provide confidence that the conducted factor analysis was appropriate and the variables were correlated highly enough to provide a reasonable basis for factor analysis. Table 9 indicates the five extracted components whose Eigenvalues were over 1.0. They accounted for 64.38 per cent of the common variance shared by the 17 predictor variables. This is above the required minimum of 60 percent of the common variance [45].

The five components extracted from factor analysis were outlined as adherence to contractual arrangement with regard to variation orders (F1), adherence to ethical procedures of procurement and transparency in budgeting and accounting system (F2), thorough feasibility study and compilation of data needed for the project (F3), methodical involvement of all key stakeholders to help in clarifying the project objectives at all stages of the project implementation (F4), and precise contract management (F5). Apparently, these issues were of great concern to respondents in evaluating the potential mitigation measures of detrimental variations. As a result, 13 predictor variables out of 17 which accounted for 64.38 per cent cumulative percentage variance explained were selected for further analysis. Figure 4 provides a plot of total variance associated with each underlying grouped factors. The figure confirms that a 5-factor model should be sufficient.

Table 9. Results of factor analysis showing the factor loadings

\begin{tabular}{|c|c|c|c|c|c|}
\hline \multirow{2}{*}{ Construction Performance Contributory Factor } & \multicolumn{5}{|c|}{ Component } \\
\hline & F1 & F2 & F3 & F4 & F5 \\
\hline Clients' involvement during construction phase & & & & 0.69 & \\
\hline Prompt written approval procedures & & & & 0.70 & \\
\hline Engagement of a project manager to manage the project & & & & 0.73 & \\
\hline Variation logic and justification & 0.77 & & & & \\
\hline Proper project scheduling (planning) & 0.74 & & & & \\
\hline Clarity of variation order procedures & 0.79 & & & & \\
\hline Clear project specifications & 0.49 & & & & \\
\hline Restricted tendering method for awarding projects & & 0.78 & & & \\
\hline Initiatives aimed at curbing corruption & & 0.70 & & & \\
\hline Teamwork spirit & & & 0.50 & & \\
\hline Proper utilization of work break down structures (WBS) & & 0.81 & & & \\
\hline Effort by client, consultant and contractor to control variation orders & & & 0.61 & & \\
\hline Comprehensive site investigations & & & 0.64 & & \\
\hline Proper use of project data compiled by client & & & 0.66 & & \\
\hline Use of knowledge base of previous related projects & & & 0.68 & & \\
\hline Control for variation orders to arise through contractual clauses & & & & & 0.79 \\
\hline Valuation of indirect effects & 0.36 & & & & \\
\hline
\end{tabular}

Notes: Extraction Method: Principal Component Analysis; Rotation Method: Varimax with Kaiser Normalization.

Table 10. Bartlett's test and KMO for the factors

\begin{tabular}{|l|l|l|}
\hline \multicolumn{2}{|l|}{ KMO and Bartlett's Test } & 0.84 \\
\hline \multicolumn{2}{|l|}{ Kaiser-Meyer-Olkin Measure of Sampling Adequacy. } & 870.10 \\
\hline \multirow{3}{*}{ Bartlett's Test of Sphericity } & Approx. Chi-Square & 136 \\
\cline { 2 - 3 } & $\mathrm{df}$ & 0.00 \\
\cline { 2 - 3 } & Sig. & \\
\hline
\end{tabular}




\section{Scree Plot}

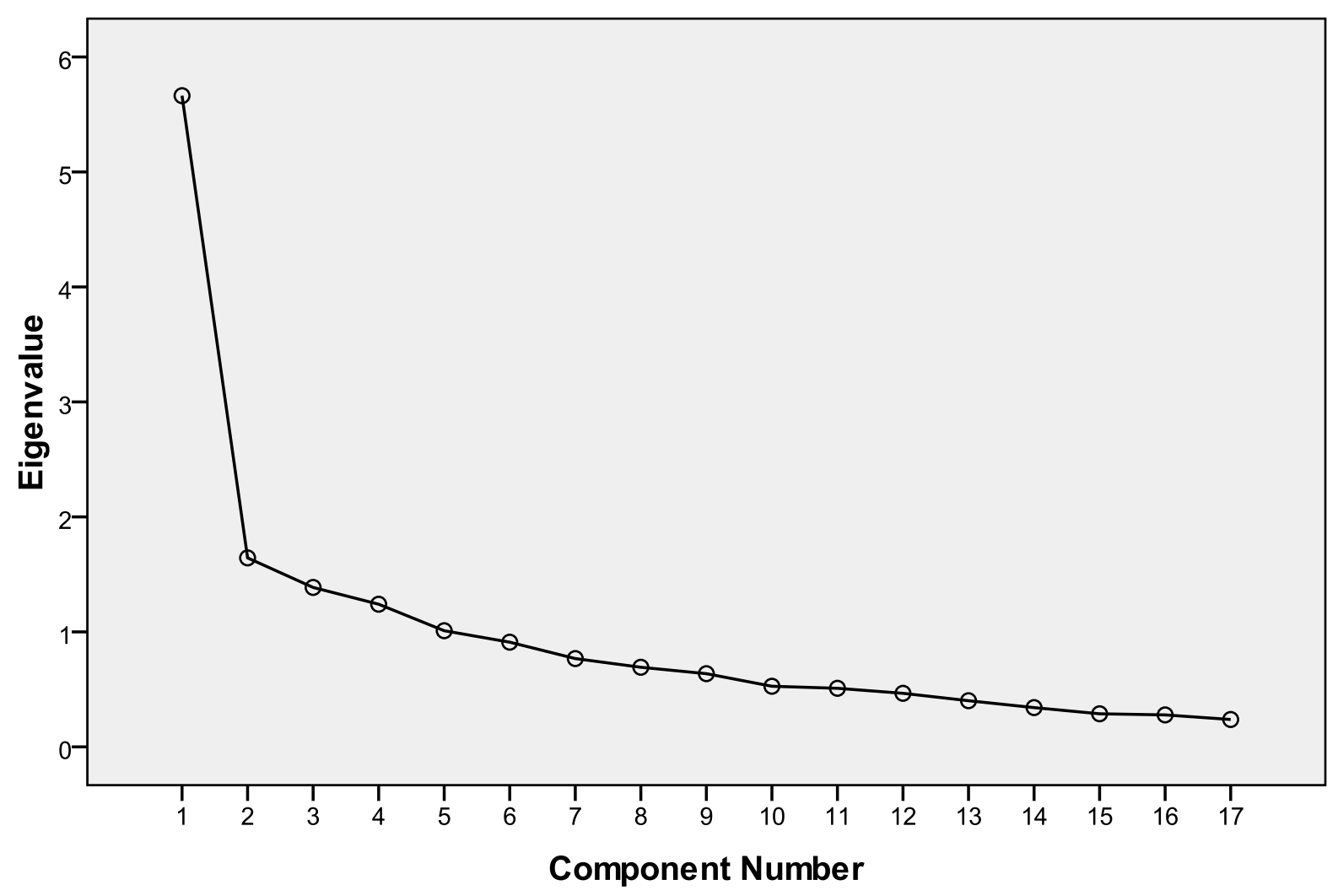

Figure 4. Scree plot of the 17 performance contributing factors

\subsection{Case Study Demonstration}

Table 11 and Table 12 show selected Case Studies of public building projects in Arusha, Tanzania to demonstrate the extent of the variation problem and the association between independent variables and dependent variables in the aspect of construction performance. Results of the case studies indicate that the causes of cost and time overruns are the reflection of what the proposed best practice model tries to address. Case Study one project incurred extra cost escalated at 2.79 per cent over the average initial cost with delays and time for completion escalated at 76.4 per cent resulting from the increase of scope of work. On Case Study two, the cost escalated at 26.53 per cent over the average initial estimated cost with delays and time of completion escalated at 73.71 per cent. Relatively, Case Study three incurred cost overrun escalated at 48.91 per cent of the original estimated contract sum with delays and time completion escalated at 200 per cent of the initial estimated duration. The nature of variations in those three projects predicts that the client and consultant combined were the predominant origin agents of variations. Impliedly, thorough project stakeholders' involvement, proper contractual arrangements, adherence to ethical procedures, thorough feasibility study and precise contract management would help to reduce detrimental variations and to enhance value for money in public building projects.

Table 11. Cost implication on each building project to variations

\begin{tabular}{|c|c|c|c|c|c|c|}
\hline \multicolumn{2}{|c|}{$\begin{array}{l}\text { Building } \\
\text { Project }\end{array}$} & $\begin{array}{c}\text { Initial Cost } \\
\text { (Tshs) }\end{array}$ & $\begin{array}{l}\text { Final Cost } \\
\text { (Tshs) }\end{array}$ & $\begin{array}{l}\text { Cost Overrun } \\
\text { (Tshs) }\end{array}$ & $\begin{array}{c}\text { Cost } \\
\text { Overrun } \\
\text { (Percentage) }\end{array}$ & Causes \\
\hline \multicolumn{2}{|c|}{ Case Study I } & 4,945,958,000.00 & $5,083,926,561.00$ & $137,968,561.00$ & $2.79 \%$ & $\begin{array}{l}\text { Increase of scope of works: } \\
\text { Re-allocation of electrical poles; Removal of } \\
\text { existing septic tanks. }\end{array}$ \\
\hline \multirow{3}{*}{$\begin{array}{l}\text { Case } \\
\text { Study } \\
\text { II }\end{array}$} & $\begin{array}{c}\text { Phase } \\
\text { I }\end{array}$ & 1,323,355,668.00 & $1,674,444,066.00$ & $351,088,398.00$ & $26.53 \%$ & \multirow{3}{*}{$\begin{array}{l}\text { Increase of scope of work due to introduced } \\
\text { basement. }\end{array}$} \\
\hline & $\begin{array}{c}\text { Phase } \\
\text { II }\end{array}$ & 1, 297,954,000.00 & $997,095,516.00$ & Nil & Nil & \\
\hline & $\begin{array}{c}\text { Phase } \\
\text { III }\end{array}$ & $1,850,560.00$ & 1,531,999,093.30 & Nil & Nil & \\
\hline \multicolumn{2}{|c|}{ Case Study III } & $2,681,850,463.00$ & 3,993,665,519.50 & $1,311,815,056.50$ & $48.91 \%$ & $\begin{array}{l}\text { Increase of scope of works due to: Re-allocation of } \\
\text { site; Introduced basement; Introduced hydraulic } \\
\text { lab; Additional staircase and lamps; Change of } \\
\text { roof design and materials; Introduced lift. }\end{array}$ \\
\hline
\end{tabular}


Table 12. Time implication on each building project to variations

\begin{tabular}{|c|c|c|c|c|c|c|}
\hline \multicolumn{2}{|c|}{$\begin{array}{l}\text { Building } \\
\text { project }\end{array}$} & $\begin{array}{c}\text { Estimated } \\
\text { period } \\
\text { (weeks) } \\
\end{array}$ & $\begin{array}{l}\text { Actual } \\
\text { period } \\
\text { (weeks) }\end{array}$ & $\begin{array}{c}\text { Time } \\
\text { overrun } \\
\text { (weeks) }\end{array}$ & $\begin{array}{c}\text { Time } \\
\text { overrun } \\
\text { (Percentage) }\end{array}$ & Causes \\
\hline \multicolumn{2}{|c|}{ Case Study I } & 34 & 60 & 26 & $76.47 \%$ & $\begin{array}{l}\text { Increase of scope of works: Re-allocation of electrical poles; } \\
\text { Removal of existing septic tanks. }\end{array}$ \\
\hline \multirow{3}{*}{$\begin{array}{c}\text { Case } \\
\text { Study } \\
\text { II }\end{array}$} & $\begin{array}{l}\text { Phase } \\
\text { I }\end{array}$ & 32 & 40 & 8 & $25.00 \%$ & \multirow{3}{*}{$\begin{array}{l}\text { Introduced basement; Delay in procurement process of } \\
\text { subcontractors and; Shortage of funds. }\end{array}$} \\
\hline & $\begin{array}{c}\text { Phase } \\
\text { II }\end{array}$ & 26 & 30 & 4 & $15.38 \%$ & \\
\hline & $\begin{array}{c}\text { Phase } \\
\text { III }\end{array}$ & 36 & 48 & 12 & $33.33 \%$ & \\
\hline \multicolumn{2}{|c|}{ Case Study III } & 48 & 144 & 96 & $200 \%$ & $\begin{array}{l}\text { Increase of scope of works: Introduced basement; Introduced } \\
\text { hydraulic lab; Additional staircase and lamps; Change of roof design } \\
\text { and materials; Introduced lift; Re-allocation of site and; Delay in } \\
\text { availability of funds. }\end{array}$ \\
\hline
\end{tabular}

\subsection{Model Layout and Discussion}

Using a practical model for mitigating detrimental variations as depicted in Figure 5 helps the project team to dramatically improve performance of construction. The model as an important tool enables the project team to identify detrimental variations and evaluate their impacts as early and accurately as possible. Significant contributing factors and performance dimensions as independent and dependent variables respectively ascertained from the analyses were used to develop the model. Consequently, the model was made up of five major components: involvement of project stakeholders; adherence to ethical procedures; thorough feasibility study; contractual arrangements; and precise contract management as methodically discussed here under.
In a construction project, it is imperative to involve project stakeholders methodically in all stages of the project life cycles. This ensures that all key stakeholders participate fully in all project activities and help clarifying the project objectives at all stages of the project implementation. This helps the project team to identify risks and evaluate their impacts as early and as accurately as possible to enhance the construction performance. Memon et al. [1] and Enshasi et al. [18] insist that client involvement and engagement of project manager to manage the project significantly contribute to performance improvement in construction projects. Moreover, issues such as proper project scheduling (planning), clarity of variation order procedures, variation logic and justification would help to improve construction performance [3,8].

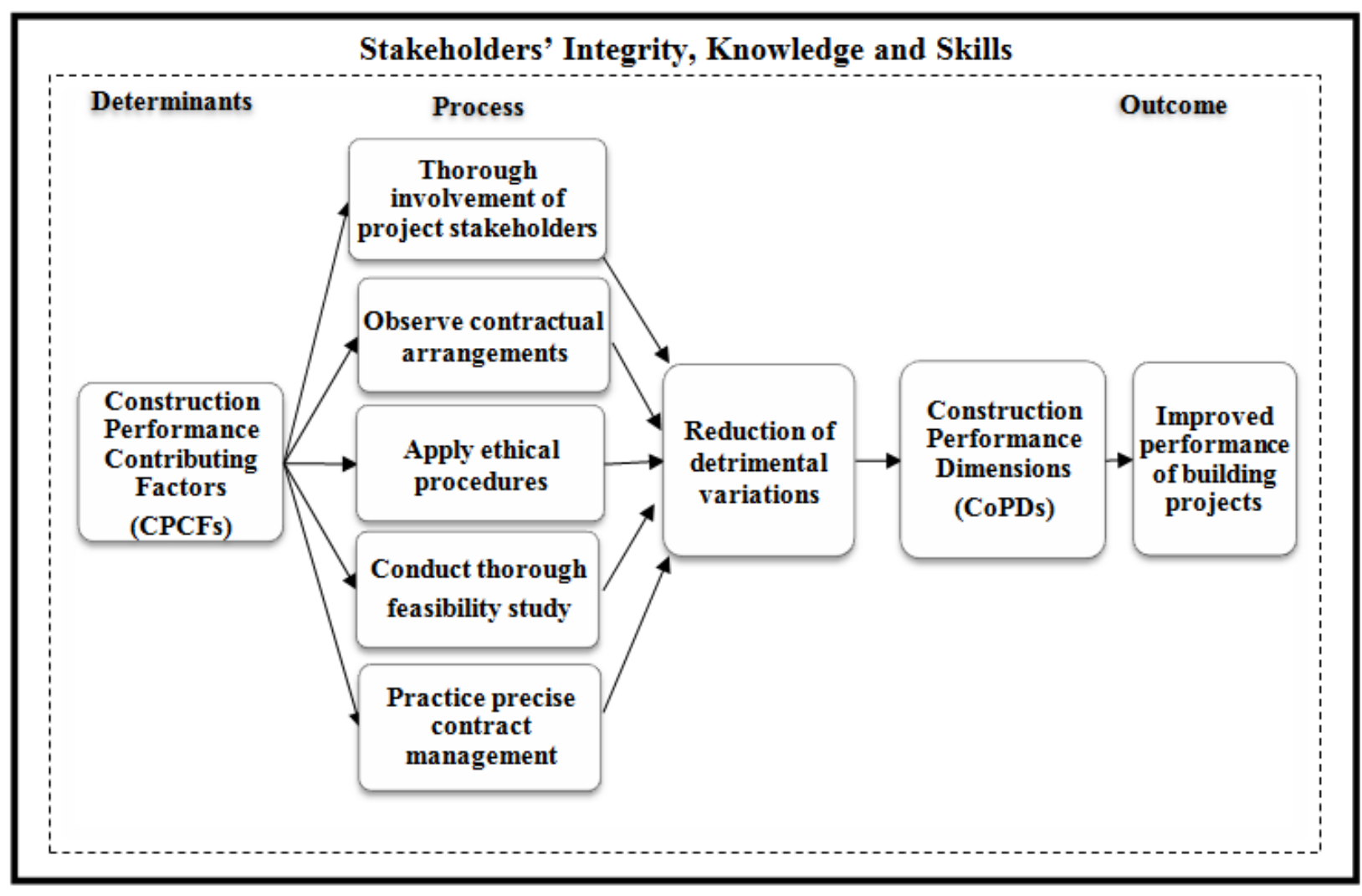

Figure 5. Detrimental variation mitigation model 
In support of best practice, the application of the highest ethical standards in construction project ensures the best achievable procurement outcomes with constrained corruption practices in the tendering process. Restricted tendering method of procurement for awarding projects and initiatives aimed at curbing corruption would minimize possible detrimental variations. This could help to improve performance of construction projects. Also, conducting thorough and broad feasibility study and compiling data needed for the project would be of great help. This can be achieved by carrying out comprehensive site investigations; use of knowledge base of previous similar projects; proper use of project data compiled by the client, and utilizing the joint effort of the client, consultant and contractor $[1,17,21]$.

Precise contract management should be practical so that the project parties meet their contractual obligations in order to deliver the specific objectives provided in the contract. Certainly, this ensures that the objectives of the contract which include supplies of goods and delivery of services or execution of works are met in a timely fashion and value for money is achieved. In practice, this means optimizing the efficiency of the processes, balancing costs and risks against returns and ideally aiming for a continuous improvement in performance over the life of the contract. Dmaidi et al. [46] advise that for a successful project, it is crucial that the requirements of the construction contract and obligations are understood and fulfilled by all project parties to achieve all contract expected benefits as efficiently and effectively as possible. Overall, this implies that project management team must possess enough integrity, knowledge and skills to deal with the day-to-day management challenges of construction changes.

\subsection{Focus Group and Model Validation}

The focus group discussions which were conducted provided a valuable insight into the perception of professionals regarding the developed model. Model validation requires not only that the model meets with known "physical law", but also that its results comply with the behaviour of the real world [13]. The aim of validation was to test the model's applicability, clarity, usefulness and deficiencies to ensure that the developed model adds value to public building projects. One-sample t-test analysis was employed to test for significance in rating the model validation items. The 2-tailed test for level of significance shows that all values of rated items in Table 13 are less than 0.05 , meaning that the ratings were significant. Likewise, the $\mathrm{t}$ values demonstrate that the rating of the items was significant since they are above zero. Results of the conducted focus group discussions regarding the developed model's applicability, clarity, usefulness, deficiency and areas of improvement are summarized and presented in the subsequent sections as responses to a list of structured questions.

\subsubsection{Applicability of the Model}

Results in Table 13 show that the overall viewpoints of respondents commended and agreed upon the model applicability $(\mathrm{M}=4.08)$. The results from analysed viewpoints of respondents endorse the structure of the model $(\mathrm{M}=4.58)$; model relevance $(\mathrm{M}=4.42)$; model amalgamation $(\mathrm{M}=4.00)$; and the best practice of the model $(\mathrm{M}=4.08)$ as they are all rated from 4.00 to 4.58 out of 5 which are far away from 3 as a cutoff point. Therefore, all rated aspects of the model's applicability provide strong evidence that the model is applicable in the construction industry of Tanzania, particularly in public building projects.

\subsubsection{Clarity of the Model}

Participants were asked to rate the model based on the set criteria under the model clarity. The analysis results in Table 13 demonstrated that the respondents' viewpoints agreed that the levels of clarity were substantial since the means of the rated items under model clarity range from 4.0 to 4.5 . Although the mean values do not guarantee a hundred percent model clarity, it clarifies stakeholders' responsibilities, improve communication and relationship among parties to enhance performance; and stimulate knowledge, skills and integrity to construction stakeholders. This is in agreement with the overall viewpoints from respondents with regard to model clarity $(\mathrm{M}=4.17)$. This provides strong evidence that the model exhibit clarity such that it is sufficient to be practised to minimise detrimental variations in public building projects in Tanzania.

Table 13. Results of focus groups discussion

\begin{tabular}{|c|c|c|c|c|}
\hline & \multirow{2}{*}{ Participants(N) } & \multirow{2}{*}{ Mean } & \multicolumn{2}{|c|}{ Test Value $=3, \mathrm{df}=11$} \\
\hline & & & $\mathbf{t}$ & Sig. (2-tailed) \\
\hline \multicolumn{5}{|l|}{ Model applicability } \\
\hline Model structure & 12 & 4.58 & 10.65 & 0.00 \\
\hline Model relevance & 12 & 4.42 & 9.53 & 0.00 \\
\hline Model amalgamation & 12 & 4.00 & 5.75 & 0.00 \\
\hline Model best practice & 12 & 4.08 & 5.61 & 0.00 \\
\hline \multicolumn{5}{|l|}{ Model clarity } \\
\hline Obligations to stakeholders & 12 & 4.42 & 9.53 & 0.00 \\
\hline Communicable & 12 & 4.00 & 8.12 & 0.00 \\
\hline Instigating knowledge, skill and integrity & 12 & 4.50 & 9.95 & 0.00 \\
\hline \multicolumn{5}{|l|}{ Model usefulness } \\
\hline Increase quality & 12 & 4.33 & 9.38 & 0.00 \\
\hline Decrease conflicts and disputes & 12 & 3.92 & 6.17 & 0.00 \\
\hline Restrict cost and time overruns & 12 & 4.42 & 9.53 & 0.00 \\
\hline \multicolumn{5}{|l|}{ Overall viewpoints on the model: } \\
\hline Applicability & 12 & 4.08 & 7.29 & 0.00 \\
\hline Clarity & 12 & 4.17 & 10.38 & 0.00 \\
\hline Usefulness & 12 & 4.17 & 7.00 & 0.00 \\
\hline
\end{tabular}




\subsubsection{Usefulness of the Model}

Table 13 indicates that the mean scores of the three rated components for model usefulness range from 3.92 to 4.42 out of 5 . Although these values do not indicate that the outcomes of the model are a hundred per cent useful, they indicate that the model is more likely to be useful when implemented. The overall respondents' viewpoint $(\mathrm{M}=4.17)$ provides strong evidence that the model is useful such that when put into practice could minimise detrimental variations and improve performance of construction.

\subsubsection{What is the Importance of the Model in Building Projects Development?}

In answering the above question, the respondents revealed that the developed model is a promising tool that could be used to improve performance of building projects from concept and design stages to tendering and construction stages. Respondents perceived that the proposed best practice model with appreciable consistency can be used by construction practitioners to reduce detrimental variations and enhance construction performance in terms of cost, time and quality. Moreover, it was pointed out that the proposed model is an appropriate tool for clarifying the position and responsibilities of each project participant that could be integrated into the required joint effort in controlling detrimental variations.

It was pointed out that the problem of communication was reported in many construction projects. The respondents felt that the developed best practice model can be used to improve the much needed communication and relationship among stakeholders towards mutual understanding of detrimental variations in construction projects. In fact, a number of comments from respondents were made about the importance of the model. It was also pointed out that the model can speed up the construction process by maintaining a high performance workflow through undisputed project parties. Additionally, the respondents observed that the model embraces integrity, knowledge, and skills that encourage the application of the highest ethical standards that ensure the best achievable procurement outcomes with constrained corruption practices in the tendering process.

\subsubsection{How Can the Model Get Improved?}

Although the model was perceived by respondents as a tool for enhancing performance in building projects, different suggestions emerged from respondents regarding the need of improving the model to enhance its performance. It was suggested that the model should be simple and unequivocal in its presentation such that project parties can understand the contents. It is also suggested that, aspects such as sufficient knowledge in contract management, noncompliance, work monitoring, work evaluation, budgeting, procurement arrangements, communication and feasibility study should be highlighted in the model. Moreover, the respondents proposed that transparency in budgeting and accounting system should be integrated into the model as this could make the model useful in its application. In fact, the expressed concerns by experts toward improvement of the model were taken into consideration and the model was improved accordingly.

\section{Conclusions and Recommendations}

\subsection{Conclusions}

The objective of the study was to develop a mitigation model that helps to mitigate detrimental variations in public building projects in Tanzania. The objective was successfully addressed by developing a proactive detrimental variation mitigation model. The model as presented in Figure 5 is developed to help project parties to identify detrimental variations and evaluate their impacts as early and accurately as possible. Literature review was carried out to identify the independent and dependent variables. Data was collected using questionnaire, focus group discussion and Case Studies. Significant independent and dependent variables were generated from the analysis and formed the basis for the developed model.

Focus group discussions were used to evaluate and validate the model, and it is found to be satisfactory, applicable and useful in reducing detrimental variations in building projects. Case Studies were carried out to demonstrate the importance of the model. Case study one project incurred extra cost escalated at 2.79 per cent over the initial cost with delays, and time for completion escalated at 76.4 per cent resulting from the increase of scope of work. Case Study two shows that the cost escalated at 26.53 per cent over the initial estimated cost with delays and time of completion escalated at 73.71 per cent. Relatively, Case Study three incurred cost overrun escalated at 48.91 per cent of the original estimated contract sum with delays and time completion escalated at 200 per cent of the initial estimated duration. The revealed cost and time overruns from conducted Case Studies is a reflection of what the proposed best practice model tries to address.

The developed detrimental variation mitigation model has five key features namely: thorough involvement of project stakeholders, adherence to contractual arrangements, adherence to ethical procedures, thorough and broad feasibility study, and precise contract management which are moderated by stakeholders' integrity, knowledge and skills. Concurrently, these features influence positive attitudes towards reduction of detrimental variations and improve performance of construction projects with regard to construction performance dimensions.

The consulted construction experts to validate the model considered the proposed model as an appropriate tool for clarifying the position and responsibilities of each project participant. They opined that, the developed integrative proactive model with relevant features, would not only pre-empt flaws in building projects, but would also help the entire project team to act prior to the occurrence of detrimental variations. Because of the benefit they expect, construction experts perceived the proposed best practice model should be used by construction practitioners to reduce detrimental variations and enhance performance in public building projects in Tanzania.

\subsection{Recommendations}

In order to advance performance in public building projects, the contributions of each stakeholder must be 
improved. The occurrence of detrimental variations that cause poor performance is about the expertise of the construction professionals. The general comments made by the study respondents indicated that issues related to skills cause detrimental variations in various ways. Hence, performance improvement in public building projects requires the improvement of the competence of the entire construction team involved in a project. Thus, based on the research objective, the study recommends the following to construction practitioners, researchers and policies governing the construction industry:

- Sufficient time should be given to design team to design the facility and prepare tender documents. This helps to avoid mistakes and lack of clarity in the tender documents. Moreover, with enough time, the design team will be able to conduct thorough feasibility study prior the design. As a result, this will minimize design discrepancies, change of specifications and insufficient working drawings.

- The selection of consultants and contractors should base on the integrity, skills and capacity to undertake the project.

- Precise contract engagements that are clear and focused on the obligations of each project part involved in a contract should be embraced in construction contracts. This ensures thorough involvement of project stakeholders and adherence to ethical procedures in a project. Furthermore, the engagement contracts should be able to provide remedies for misconduct and failure to discharge duties by project participant, as this promotes adherence of ethical procedures in executing the project.

- The competence improvement within project organization should be a continuous process to encourage professionalism. Professionalism as a combination of high skills and standards enhance performance in construction projects and;

- Further research is suggested on developing an appropriate approach of capturing data with regard to detrimental variations in building projects.

\section{Acknowledgements}

The authors wish to gratefully acknowledge, with thanks, the Arusha Technical College (ATC) of Tanzania and Makerere University (MAK) of Kampala Uganda for providing the required necessary resources that made this research possible. We are thankful to institutions, the consultants, the contractors and individuals for providing data needed for the study.

\section{Competing Interests}

The authors have no competing interests

\section{References}

[1] Memon, A. H., Rahman, I. A., \& Hasan, M. F. A., "Significant Causes and Effects of Variation Orders in Construction Projects," Research Journal of Applied Sciences, Engineering and Technology, 2(21), 4494-4502, 2014.
[2] Ismail, A., Pourrostam, T., Soleymanzadeh, A., \& Ghouyounchizad, M., "Factors Causing Variation Orders and their Effects in Roadway Construction Projects," Research Journal of Applied Sciences, Engineering and Technology, 4(23), 4969-4972, 2012.

[3] Ubani, E., Nwachukwu, C., \& Nwokonkwo, O. "Variation Factors of Project Plans and their Contributions to Project Failure in Nigeria," American Journal of Social and Management Sciences, 1(2), 141-149, 2010.

[4] Mohemad, R., Hamdan, A. R., Othman, E. Z. A. \& Noor, N. M. M., "Decision Support Systems (DSS) in Construction Tendering Processes,” International Journal of Computer Science Issues, 7(1), 35-45, 2010.

[5] Park, Y., \& Papadopoulou, T. C., "Causes of Cost Overruns in Transport Infrastructure Projects in Asia,” Built Environment Project and Asset Management, 2(2), 195-216, 2012.

[6] Senaratne, S., \& Sexton, M., "Managing Construction Project Change: A Knowledge Management Perspective," Construction Management and Economics, 26(12), 1303-1311, 2008.

[7] Motawa, I. A., "A Systematic Approach to Modelling Change Processes in Construction Projects," The Australasian Journal of Construction Economics and Building, 5(1), 23-31, 2005.

[8] Moghaddam, A. G., "Change Management and Change Process Model for the Iranian Construction Industry,” International Journal of Management Business Research, 2(2), 85- 94, 2012.

[9] Kolawole, A. R., Kamau, K. P., \& Munala, G., "Change Order Process Model for the Nigerian Construction Industry,” Journal of International Academic Research for Multidisciplinary, 4(1), 119132, 2016.

[10] Hao, Q., Shen, W., Neelamkavil, J., \& Thomas, R., "Change Management in Construction Projects," CIB W78 International Conference on Information Technology in Construction, Santiago, Chile. 2008.

[11] Babatunde, S. O., "Quantitative Assessment of Cost and Time Implication of Susceptibility of Building Elements to Variation in Nigeria," International Journal of Sustainable Construction Engineering and Technology, 4(2), 93-103, 2013.

[12] Arain, F. M. \& Pheng, L. S., "The Potential Effects of Variation Orders on Institutional Building Projects," Facilities, 23(11/12), 496-510, 2005.

[13] Love, P. E. D., Irani, Z., \& Edwards, D. J., "A Rework Reduction Model for Construction Projects," IEEE Transactions on Engineering Management, 51(4), 426-440, 2004.

[14] Hwang, B., \& Low, L. K. "Construction Project Change Management in Singapore: Status, Importance and Impact," International Journal of Project Management, 30(2012), 817-826, 2011.

[15] Arain, F. M., "Strategic Management of Variation Orders for Institutional Buildings: Leveraging on Information Technology," Paper Presented at the PMI Global Congress Proceedings, Toronto, 1-17, 2005.

[16] Mlinga, R. S., "Ethics in Public Procurement: A Missing Link in the Education and Training of Construction Industry Practitioners," Paper presented at the Forum Proceedings, Construction Industry Forum, Organised by the National Construction Council of Tanzania, $12^{\text {th }}-13^{\text {th }}$ September, Dar es Salaam, National Construction Council, 1-19, 2008.

[17] Subramani, T., Sruthi, P. S. \& Kavitha, M., "Causes of Cost Overrun in Construction,” Journal of Engineering, 4(6), 1-7, 2014.

[18] Enshasi, A., Mohamed, S., \& Abushaban, S., "Factors affecting the Performance of Construction Projects in the Gaza Strip," Journal of Civil Engineering and Management, 15(3), 269-280, 2009.

[19] Aiyetan, A. O., \& Smallwood, J. J., "Professionals' Perceptions Regarding Factors Influencing Project Delivery Time," Proceedings TG59 People in Construction, $12^{\text {th }}-14^{\text {th }}$ July, Port Elizabeth, South Africa, 225-234, 2009.

[20] Rajeev, S., \& Kothai, P. S., "Study on the Influence of Stakeholders in Construction Projects," Journal of Construction Engineering and Project Management, 4(2), 8-11, 2014.

[21] Emuze, F. A., \& Smallwood, J. J., "Improving Project Delivery in South African Construction," In: Proceedings of $27^{\text {th }}$ Annual ARCOM Conference, September 5-7, Bristol, United Kingdom, 921-930, 2011.

[22] Tadayon, M., Jaafar, M., \& Nasri, E., "An Assessment of Risk Identification in Large Construction Projects in Iran,” Journal of Construction in Developing Countries, 1, 57-69, 2012. 
[23] Ammar, M. A., Elsamdomy, A. A., \& Rabie, A. A., "Risk Allocation and Mitigation in the Egyptian Barrage Projects," Proceedings of the $13^{\text {th }}$ International Conference on Structural and Geotechnical Engineering, December 27-29, Ain Shams University, Cairo, 180-190, 2009.

[24] Priyantha, T. H. S., Karunasena, G., \& Rodrigo, V. A. K., "Causes, Nature and Effects of Variations in Highways," Journal of Built Environment - Sri Lanka, 09-10(01-02), 14-20, 2011.

[25] Ibbs, W. "Construction Change: Likelihood, Severity, and Impact on Productivity,” Journal of Legal Affairs and Dispute Resolution in Engineering and Construction, 4(3), 67-73, 2012.

[26] Simpeh, E. K., Ndihokubwayo, R., \& Love, P. E. D., "Field Diagnosis of Causes and Effects of Rework in Higher Education Residential Facilities,” Journal of Construction, 4(1), 1-11, 2011.

[27] Alinaitwe, H. M., Improvement of Labour Performance and Productivity in Uganda's Building Industry, Ph.D Thesis, Sweden: Lund University, 2008.

[28] Taggart, M., Koskela, L., \& Rook, J., "The Role of the Supply Chain in the Elimination and Reduction of Construction Rework and Defects: An Action Research Approach," Construction Management and Economics, 32(7-8), 829-842, 2014.

[29] Jelodar, M. B., Yiu, T. W., \& Wilkinson, S., "Systematic Representation of Relationship Quality in Conflict and Dispute for Construction Projects," Construction Economics and Building, 15(1), 89-103, 2015

[30] Chikere, C. C., \& Nwoka, J., “The Systems Theory of Management in Modern Day Organizations: A Study of Aldgate Congress Resort Limited Port Harcourt,” International Journal of Scientific and Research Publications, 5(9), 1-7, 2015.

[31] Kombo, D. K., \& Tromp, D. L. A., Proposals and Thesis Writing: An introduction, Nairobi: Pauline's Publications Africa, 2006.

[32] Palinkas, L. A., Horwitz, S. M., Green C. A., Wisdom, J. P., Duan, N., \& Hoagwood, K., "Purposeful Sampling for Qualitative Data Collection and Analysis in Mixed Method Implementation Research,” Adm Policy Ment Health, 42(5), 533-44, 2015.

[33] Tongco, D. C., "Purposive Sampling as a Tool for Informant Selection,” A Journal of Plants, People and Applied Research, 5, 147-158, 2007.
[34] Rahi, S., "Research Design and Methods: A Systematic Review of Research Paradigms, Sampling Issues and Instruments Development," International Journal of Economics and Management Sciences, 6(2), 1-5, 2017.

[35] Mohammad N., Ani, A. I. C., Rakmat, R. A. O. K., \& Yusof, M. A., "Investigation on the Causes of Variation Orders in the Construction of Building Project: A Study in the State of Selangor, Malaysia,” Journal of Building Performance, 1(1), 73-82, 2010.

[36] Fellows, R. \& Liu, A., Research Methods for Construction, Chichester: Wiley Blackwell Publishing Ltd, 3th edition, 2008.

[37] Wong, L. P., "Focus Group Discussion: A Tool for Health and Medical Research,” Journal of Medical Education, 49(3), 256-261, 2008.

[38] Stewart, D. W., Shamdasani, P. N., \& Rook, D. W., Focus Groups Theory and Practice, Newbury Park: Sage Publications, 2nd edition, 2007.

[39] Spillane, J., \& Oyedele, L., "Strategies for Effective Management of Health and Safety in Confined Site Construction," Australasian Journal of Construction Economics and Building, 13(4), 50-64, 2013.

[40] Cohen, L., Manion, L., \& Morrison, K., Research Methods in Education, New York: Routledge, 6th edition, 2007.

[41] Breen, R. L., "A Practical Guide to Focus-Group Research,” Journal of Geography in Higher Education, 30(3), 463-475, 2006.

[42] Yin, R. K., Case Study Research: Design and Methods, London: SAGE Publications, 4th edition, 2009.

[43] Suryanarayana, T. M. V., \& Mistry, P. B., "Principal Component Regression for Crop Yield Estimation,” Springer Briefs in Applied Sciences and Technology, 17-25, 2016.

[44] Manerikar, V., \& Manerikar, S., “Cronbach’s alpha,” A Peer Reviewed Research Journal - aWEshkar, XIX (1), 117-119, 2015.

[45] Hair, J. F., Anderson, R. E., Tatham, R. L., \& Black, W.C., Multivariate Data Analysis, Upper Saddle, New Jersey: PrenticeHall Inc, 7th edition, 2010.

[46] Dmaidi, N., Dwaikat, M., \& Shweikh, I., "Construction Contracting Management Obstacles in Palestine," International Journal of Construction Engineering and Management, 2(1), 1522, 2013. 